\title{
Phonological typology, rhythm types and the phonetics-phonology interface. A methodological overview and three case studies on Italo- Romance dialects
}

\section{Stephan Schmid}

\section{Introduction}

Phonological typology has mainly concentrated on phoneme inventories and on implicational universals, whereas the notion of 'language type' appears to be less appealing from a phonological perspective. An interesting candidate for establishing language types on the grounds of phonological or phonetic criteria would have come from the dichotomy of 'stress-timing' vs. 'syllable-timing', if instrumental research carried out by a number of phoneticians had not invalidated the fundamental claim of the so-called 'isochrony hypothesis'. Nevertheless, the idea of classifying languages according to their rhythmic properties has continued to inspire linguists and phoneticians, giving rise to two diverging methodological perspectives. The focus of the first framework mainly lies on how phonological processes relate to prosodic domains, in particular to the syllable and to the phonological word. Along the second line of research, new quantitative metrics have been proposed in order to grasp the rhythmic properties of speech signals in different languages.

This contribution aims at bridging the gap between phonological and phonetic approaches to linguistic rhythm by paying particular attention to methodological issues. The second section gives an overview of basic issues and major findings in the field of phonological typology, focusing on segment inventories, syllable structure and prosodic features. The third section is devoted to language rhythm and the different ways it has been conceived of in the last fifty years. Finally, the fourth section is dedicated to three case studies of a number of Italo-Romance dialects dealing with vowel systems, syllable types and rhythm metrics. 


\section{Phonological typology}

\subsection{Phonology and linguistic typology}

At the first International Congress of Linguists in 1928, the members of the linguistic circle of Prague postulated a division of labor between phonetics and phonology, arguing that researchers should distinguish between the physical manifestation of speech sounds and their role as functional elements of a language system. Phonology then received its foundations as an autonomous subdiscipline of linguistics in the influential monograph of Trubetzkoy (1939), which is based on the scrutiny of numerous descriptions of languages from Europe, Asia, Africa and even North America. The Grundzüge offer a compendium of what was known about the structure of segment inventories at that time and, in a sense, they also bear some elements of a typology avant la lettre; nevertheless, Trubetzkoy's goal was essentially methodological, aiming at establishing categories that are useful for discovering the sound patterns of human language(s). Some of the analytical tools elaborated within this enterprise were destined to become part of modern linguistic reasoning, e.g. the idea of 'feature bearing' (merkmalhaft) which gave rise to the notion of 'markedness', a key term in linguistic typology (cf. Croft 1990: 64).

Among the fundamental texts in the history of phonological typology one should mention the seminal contribution of another member of the Prague circle, namely Jakobson's (1941) study on child language and aphasia. Often blamed for its alleged reductionism and empirical weakness, this essay not only invoked the parallelisms between language acquisition and language typology (Typologie der Völkersprachen; cf. Jakobson 1941, $\S 31$ ), but it also laid the ground for the concept of 'implicational universals', maintaining that synchronic 'sound laws' were determined by a solidarité irréversible (Jakobson 1941, §§14-15). The argument runs as follows: if children acquire a given speech sound B later than speech sound A, the languages of the world may not contain B without also having A.

Precisely this method of stating generalizations on human language was developed in Greenberg's (1966a) seminal work on language universals of morphology and word order, which has been considered the foundation of 'linguistic typology' as a proper field of scientific inquiry (Croft 1990: 2). Another pioneering paper by Greenberg (1966b) also contains a chapter devoted to phonology, dealing with phenomena such as the voicing of consonants, vowel nasalization and vowel quantity. In this analysis, marked- 
ness relations are derived from the examination of token frequencies in a small number of languages, demonstrating that voiced stops, nasal vowels and long vowels are more marked than unvoiced stops, oral vowels and short vowels. The rapid growth of linguistic typology as a research area lead to the four volumes of Universals of Human Language (Greenberg et al. 1978), the second of which is entirely dedicated to phonology, offering thirteen studies on particular topics such as vowel systems, nasal vowels, consonant clusters, phonological processes, tone, intonation, and the like.

If phonology played an essential role in the birth of linguistic typology, both in its methodological foundations and in the topics under investigation, the further development of the field showed a clear preference for syntax and morphology as major concerns of the typological research agenda. The rather marginal status of phonology is also reflected by the contents of later publications which present the state of the art in linguistic typology, e.g. the introduction written by Croft (1990), the two HSK volumes on typology and universals (Haspelmath et al. 2001), and the World Atlas of Language Structures (Haspelmath et al. 2005, henceforth WALS).

In any case, it seems that for many years phonological typology has mainly been a concern of phonologists (and to some extent also of phoneticians), rather than of typologists (cf. Hyman 2007). ${ }^{1}$ On the methodological grounds laid at Stanford by the impact of Greenberg's ideas, the most ambitious project was carried out at UCLA under the guidance of Ian Maddieson, focusing on segment inventories and implicational universals (2.2). Phonotactic analyses are not as easily available as descriptions of phoneme inventories, and this might be one of the reasons why syllabic typology developed later and in a more heterogeneous manner (2.3). As regards prosody, the different features - such as tone, accent, and intonation - have often been treated separately, but strong efforts are being made in gathering comparative evidence from an increasing number of languages (2.4).

An interesting methodological difference between the different threads of typological linguistics comes from the observation that implicational universals have been formulated on the levels of syntax, morphology, and phonology, whereas the notion of 'language type' (cf. Croft 1990: 27-43) has most often been used in morphology (hence the distinction between inflectional, agglutinating and isolating languages) and for word order (where languages are classified as belonging to, e.g., the SVO or the SOV type). In the field of phonological typology, the concept of a linguistic type has played a rather marginal role until recently (cf. 3.2), since scholars have mainly focused on individual phenomena that can be analyzed in a binary 
way (or in terms of implications) rather than adopting a generalizing approach to typological classification. Still, nothing contradicts the notion a priori that the sound shape of a particular language may exhibit features that are inherently related to one another and that languages belonging to different genetic groupings adhere to an abstract structural model that one might conceive of in terms of a 'phonological type'. Indeed, there have been a few isolated proposals which classified languages into discrete phonological types.

For instance, Milewski (1970: 71-74) operated a binary distinction between 'vocalic' and 'consonantal' languages, depending on how a particular phoneme inventory departs from what he calls the universal 'primary system' consisting of 10 elements (the vowels / $\mathrm{i} \mathrm{a} \mathrm{u} /$, the stops $/ \mathrm{p} \mathrm{t} \mathrm{k/,} \mathrm{the}$ nasals $/ \mathrm{m} \mathrm{n} /$ plus one spirant and one liquid). In a language belonging to the 'vocalic type' like French, the ratio between primary and secondary elements is greater than zero, whereas in a language of the 'consonantal type' like Polish the ratio is below zero. In a nutshell, Milewskis typology is based on assumptions about the universality of certain segment types (the primary system) and the ratio between vowels and consonants within a phoneme inventory.

Now, the ratio between the number of consonants (C) and the number of vowel qualities (VQ) is also represented as an approach to phonological typology in WALS (cf. Maddieson 2005c), allowing a division of languages into five categories, namely those with a low $(<2)$, a moderately low (2-2.75), an average (2.75-4.5), a moderately high (4.5-6.5), and a high $\mathrm{C} / \mathrm{VQ}$ ratio $(>6.5)$. Nevertheless, it is clear that we are not dealing with language types in the sense of feature constellations, but rather with a single typological parameter. Moreover, an analysis of a 680 languages reveals no predictable relationship between the number of vowels and consonants in a segment inventory (Maddieson 2011: 541-542; cf. also Maddieson 2005c), and we may recall that the "normal autonomy of the two phonemic patterns" had already been invoked by Martinet (1962: 75).

Still, the consonant-vowel-ratio appears as a parameter of the "prosodic typology of language" proposed by David Gil (1986). This holistic approach distinguishes between two basic language types which are defined by a number of phonological and other structural features: 'iambic' languages would have fewer segments in a syllable, a high consonant-vowelratio and SOV as the basic word order, whereas 'trochaic' languages would present more segments in a syllable, a low consonant-vowel-ratio and SVO as the basic word order. For our purpose it is interesting to note that, at a 
certain point, Gil (1986: 197) refers to iambic languages as "stress-timed" and to trochaic languages as "syllable-timed" (cf. 3.1).

Though not quoted by Gil, a similar holistic typology had been proposed by Donegan and Stampe (1983) on the basis of a typological study of the Munda and Mon-Khmer languages. According to their analysis, the MonKhmer languages are characterized by iambic stress pattern, isoaccentual timing, complex syllable structure and SVO word order, whereas the Munda languages display the opposite characteristics, i.e. trochaic stress pattern, isosyllabic timing, simple syllable structure and SOV word order. As we can see, the feature couplings of Donegan and Stampe (1983) and Gil (1986) do not coincide, and they also differ with regard to other parameters such as tone and morphological word structure. It lies outside the scope of this contribution to discuss these typologies in greater detail, but we will briefly return to these issues when discussing the phonological reinterpretation of the traditional isochrony hypothesis (cf. 3.2).

Now, before roughly sketching some of the major topics in phonological typology (segment inventories, phonotactics, prosody), let us point out a methodological aspect which turns out to be of particular relevance to the present study, i.e. the size of the language sample and to what degree it can be considered as representative. In a 'general typology' approach, the sample size of the languages taken into account is supposed to be as large as possible and as balanced as possible in terms of genetic language families. Another possibility, however, is to choose a sample of genetically related language varieties; it is precisely such a 'limited typology' approach (Ineichen 1991: 21) we will adopt in the three case studies on ItaloRomance dialects (cf. 4). ${ }^{2}$

\subsection{Segment inventories and phonological universals}

As already mentioned, the bulk of typological work in phonology has dealt with vowel and consonant inventories. For instance, descriptions of 209 languages had been gathered in the Stanford Phonology Archive Project, from which Crothers (1978) carried out a detailed typological analysis of vowel systems. However, the most important enterprise in phonological typology is the UCLA Phonological Segment Inventory Database (UPSID). The first edition included 317 languages and allowed already for a number of interesting generalisations (Maddieson 1984). Subsequently, the database was enlarged to 451 languages (Maddieson and Precoda 1990). ${ }^{3}$ Since 
then, the UPSID has been updated to include 637 languages (Maddieson 2011: 535).

The study of segmental typology provides different kinds of information about the vowel and consonant systems of the world's languages. Firstly, it allows for some descriptive statistics about the size of segment inventories. Secondly, a few absolute and a number of implicational universals about segmental patterns have emerged. Thirdly, some scholars have tried to explain these patterns on the ground of general principles regarding human communication.

The size of consonant inventories varies from 6 in Rotoka to 128 in !Xóõ. Most frequently, though, languages have little more than 20 consonants, as is shown by the mean (22.7), the median (21) and the modal value (22) in the extended UPSID sample of 563 languages; a subdivision into five categories - small, moderately small, average, moderately large, large - yields a normal distribution around these values of central tendency (Maddieson 2005a, 2011: 540-541). Vowel systems may use from 2 to 14 different qualities (with a higher number of phonemes if length is taken into consideration as well), and there is again a clear central tendency, the mean being close to 6 and the modal number being 5 (Maddieson 2005b, 2011: 541).

Besides the tendencies regarding the size of segment inventories, there are also some general qualitative patterns in vowel and consonant systems which can be described in terms of 'absolute' and 'implicational' universals. Phonological universals of the absolute type - "all languages have stop consonants" and "all languages have at least two heights of vowel qualities" - are scarce and offer only elementary insights into the sound pattern of human languages; more interesting are 'implicational statements' (Maddieson 2011: 544) about the probability of particular segments to occur in a given language. Such generalizations - which may always have some counterexamples - are in line with Jakobson's solidarité irréversible and Milewski's 'primary system' (cf. 2.1): some 'basic' speech sounds have been observed to be more frequent among the languages of the world, while complex sounds tend to occur mostly in inventories with many elements.

This brings us to the problem of how to interpret the implicational findings. Quite naturally, some explanations invoke ease of articulation as a basic principle: for instance, Maddieson (2011: 535) convincingly argues that voiced fricatives are typologically marked, because frication and voicing are difficult to combine in terms of aerodynamic and gestural control. 
As regards vowels, Martinet (1962: 79-80) attributed the higher frequency of front vowels to the greater size of the anterior mouth cavity. Still, the majority of phoneticians and phonologists nowadays would subscribe to a more perceptual point of view. This is the case for the 'dispersion theory' (Liljencrants and Lindblom 1972), which states that phonemes tend to be maximally distant in the acoustic vowel space in order to enhance perceptual contrast; similarly, the 'dispersion-focalization theory' (Schwartz et al. 1997) explains the perceptual salience of rounded front vowels - which are marked in terms of dispersion - as a consequence of their formant proximity. Thus, phonological universals appear to be not only functionally motivated, but to a certain extent also phonetically grounded. ${ }^{4}$

We will return to the typology of vowel systems on the occasion of our first case study on Italo-Romance dialects (4.1), but let us first consider two topics which are of paramount importance for a typology of language rhythm: phonotactics and prosody.

\subsection{Phonotactics and syllable structure}

It is an obvious observation that phonological systems differ not only paradigmatically, i.e. with regard to the segments used to build contrasts among words, but also syntagmatically, i.e. with regard to the combinations of segments they allow for. The relevance of phonotactics for a phonological typology was pointed out by Martinet (1962: 75) and the universally unmarked status of the CV syllable had already been postulated by Jakobson (1941: $\S \S 23-24)$. Nevertheless, it seems that phonotactic typology has not been practiced to the same degree as segmental typology; this is maybe due to the fact that descriptions of segment inventories are more easily available than descriptions of syllable templates.

There are some exceptions, however. One of the first typological investigations on phonotactic patterns was provided by Greenberg (1978), who on the basis of a survey of 104 languages - formulated no less than 40 universals about initial and final consonant clusters. Some of these implicational statements are related to the size of consonant clusters, whereas others refer to the phonetic content of consonant clusters and coincide with the idea that segments are sequenced within the syllable along a scale of 'sonority' (cf. below).

Even if the UPSID project was primarily concerned with segment inventories, the possible syllables were calculated for 9 selected languages, yielding a range from 173 syllables in Hawaiian to 23,638 syllables in Thai; 
a general conclusion was that "syllable inventory size does not depend heavily on segment inventory size" (Maddieson 1984: 23). Recent work in syllabic typology has divided a sample of 486 languages into three types (Maddieson 2005e): 61 languages (12.6\%) only allow a 'simple' syllable structure $(\mathrm{CV})$, whereas 274 languages $(56.4 \%)$ permit a 'moderately complex' syllable structure with templates such as CCVC; finally, 151 languages (31\%) may have 'complex' syllable structures, e.g. CCCVCCC. A more refined syllabic typology would not only add further information about consonant clusters in word-internal position and at the margins of the word (Maddieson 2011: 546-547), but it would also specify which segment classes may occur in a particular phonotactic slot.

One analogy between the typologies of segments and syllables comes from token frequency. Even in languages with a complex syllable structure - as in the case of most European languages - the most frequent syllable types are CV and CVC: this holds for German, English, Spanish and French (Delattre 1965: 41), Italian (Schmid 1999a: 159) and the Swiss German dialects of Berne and Zurich (Keller 2008: 61). Nevertheless, there are differences between the Germanic and the Romance languages which might be relevant from the perspective of rhythm typology (cf. 3.2).

Useful generalizations for a phonotactic typology have been formulated by Theo Vennemann (1988) in a study in comparative diachronic phonology, postulating a number of 'preference laws for syllable structure' on the basis of two universal preferences. According to the first tendency, languages prefer $\mathrm{CV}$ as the universally unmarked syllabic template; therefore, $\mathrm{CCV}$ and $\mathrm{CVC}$ are more marked than $\mathrm{CV}$, and CCVCC is more marked than CCVC etc. The second preference comes from the observation that, if consonant clusters occur, segments tend to be sequenced in order to maximize their contrast in terms of 'sonority' (or 'consonantal strength'), which normally increases (or decreases) from the syllable margins towards the nucleus (cf. Vennemann 1988: 9) .

For our purpose, it is important to note that the typological markedness of a syllable pattern can be defined in terms of its numerical complexity and its adherence to the sonority principle; this is of particular relevance for the phonological analysis of rhythm we adopt (cf. 3.2, 4.2).

\subsection{Prosodic typology}

Typological studies of prosody have followed two main approaches. The 'holistic' approach is essentially tied to the notion of rhythm (cf. 2.1, 3.2) 
and devoted to the definition of 'language types'. The prevailing line of research, however, is more 'atomistic' in nature, since it is concerned with single typological 'factors' or 'prosodic features' (Maddieson 2011: 536) such as intonation, tone, vowel harmony, and word accent.

The study of intonation - i.e. of the modulations of fundamental frequency within an utterance - hardly allows for the formulation of linguistic universals. This is due not only to the many linguistic and paralinguistic functions of intonation, but also to the continuous nature of fundamental frequency, which raises intrinsic difficulties to any analysis in terms of discrete entities. Not suprisingly, WALS does not contain a map or a chapter dedicated to intonation. Nevertheless, considerable efforts have been made to gather comparative data from an increasing number of languages; for instance, the volume edited by Hirst and Di Cristo (1998) contains descriptions of the intonation systems of 22 (mostly European) languages. In some cases (e.g. Jun 2005), similar comparative entreprises are bound to a particular theoretical framework such as the so-called ToBI (Tones and Break Indices) notation; for an alternative approach to the study of intonation see Siebenhaar and Leemann (this volume).

Tones, i.e. the occurrence of lexically distinctive modulations of f0, have been fruitfully described with typological methods (cf. Maddieson 1978, Hyman 2001). From a sample of 527 languages (Maddieson 2005f), $307(58.2 \%)$ are reported to have no lexical tones, whereas the tonal languages can be divided into two major classes: 132 languages $(25.1 \%)$ have 'simple' tone systems with a two-way contrast (high vs. low) and 88 languages $(16.7 \%)$ have 'complex' tone systems. There seems to be only a loose correlation between tonal complexity and segment inventory size, and the relationship with syllable complexity is not entirely clear (Maddieson 2005f).

Word accent is a prosodic feature that has attracted increasing interest over the last years, often from the perspective of phonological theory. Applying a typological methodology, a sample of 461 languages (Maddieson 2011: 539) can be divided into three types. In 195 languages (42.3\%) accent placement is predictable (either on the first, the last or the penultimate syllable of the word), whereas in 131 languages (28.4\%) accents may fall on different syllables within the word (sometimes even creating minimal pairs); finally, 135 languages $(29.3 \%)$ do not have an accent within the domain of the phonological word.

By contrast, a metrical approach to prosodic typology assumes the foot, rather than the word, as the basic unit for the analysis of accentual systems. 
Such a rationale is behind the StressTyp database, which nowadays includes 510 languages and has substantially contributed to WALS. ${ }^{5}$ Such a typology yields two basic metrical systems, i.e. the trochaic type (where the lefthand syllable of the foot is strong) and the iambic type (where the righthand syllable of the word is strong). A classification of 323 languages (van der Hulst and Goedemans 2005) assigns 153 languages (47.4\%) to the trochaic type and $31(\%)$ to the iambic type; 41 languages $(12.7 \%)$ have either a dual system or an undetermined foot type, whereas 98 languages $(30.3 \%)$ have no "rhythmic stress". For our purpose, it is interesting to note that "trochaic" and "iambic" are labels of Gil's (1986) holistic approach (cf. 2.1 ), but here the dichotomy is explicitly meant to refer to "rhythm types" (van der Hulst and Goedemans 2005).

Now, linguistic rhythm can be defined in two different ways, either in terms of prominence relations (as is the case of metrical phonology) or in a more 'platonic' fashion, i.e. as repeated sequences of structured events. The second approach is at the basis of a phonetically oriented research tradition on timing (cf. Maddieson 2011: 536-537), which is of particular interest for the purpose of prosodic typology; in this vein, rhythm types can also be considered as a combination of interacting features. This brings us to the topic of the next section.

\section{Rhythm typology}

3.1. The isochrony hypothesis: 'stress-timed' vs. 'syllable-timed'

Probably, the phenomenon of speech rhythm has attracted more interest among phoneticians than among phonologists. This line of research takes as its point of the departure the so-called 'isochrony hypothesis' (Pike 1945, Abercrombie 1967), which distinguishes between two major types of languages termed 'stress-timed' and 'syllable-timed' (or 'isoaccentual' and 'isosyllabic'); it has been claimed that the Germanic languages belong to the former type, whereas the Romance languages belong to the latter. In its original form, the isochrony hypothesis makes two basic claims: every language belongs to one particular rhythm type, and rhythm types are based on a timing unit (e.g., the syllable or the foot), which is supposed to occur in regular sequences of intervals with equal durations (cf. Auer and Uhmann 1988: 217). 
As is well-known, the classical isochrony hypothesis has been invalidated on empirical grounds. Starting in the 1970s, acoustic measurements carried out with different languages proved that in the alleged syllabletimed languages the duration of syllables varies according to the number of their segments, as much as in the alleged stress-timed languages the duration of feet varies according to the number of their syllables (cf. the research overview in Auer and Uhmann 1988: 219-237). Nevertheless, several attempts have been made to save the idea behind the isochrony hypothesis which continued to be intuitively plausible: for instance, isochrony could be an effect of perception - rather than a mechanism of speech production - or even pertain to the realm of phonology (cf. Bertinetto 1989: 101-120). Let us examine the second hypothesis in more detail.

\subsection{Two phonological types: syllable and word languages (Auer 1993)}

The phonological turn in the study of language rhythm appeared in the 1980s (cf. Dauer 1983) and maintained two basic claims. Firstly, since rhythm types cannot be found in the speech signal itself, they rather derive from a bundle of properties of the phonological system; most important are the complexity of syllable structure and the reduction of unstressed vowels. Secondly, rhythm types are not absolute categories, but rather constitute poles of a typological continuum, allowing for mixed or intermediate types (cf. Auer and Uhman 1988: 244-253; Bertinetto 1989: 108-110).

This line of reasoning received its most elaborate formulation in the prosodic typology proposed by Peter Auer (1993). Drawing on a critical review of earlier holistic approaches to language rhythm (Dauer 1983, Donegan and Stampe 1983, Gil 1986), this study analyzes a sample of 34 genetically different languages by testing the correlations between more than a dozen phonological phenomena; moreover, it proposes a conceptual shift from the traditional labels of stress-timing vs. syllable-timing towards a new typological dichotomy which opposes 'syllable languages' to 'word languages' (cf. also Auer 2001: 1395-1398).

Syllable-rhythm and word-rhythm are conceived of as prototypes, and in fact the 34 languages of the sample may be ordered along a continuum ranging from the syllable pole towards the word pole with many intermediate or mixed languages in between - on the basis of a number of prosodic parameters (Auer 1993: 94). The notions of 'syllable rhythm' and 'word rhythm' thus meet the requirements of a 'language type', viewed as an abstract structural model that emerges from the coexistence - and probably 
from the inherent interdependence - between different parts of the phonological system, the central parameter being the prosodic domain to which features and processes refer to, i.e. the syllable or the word.

Table 1 lists a number of selected parameters which form part of this typological framework. The first two parameters, i.e. syllable complexity and adherence to the sonority sequencing principle, will be applied to a number of Italo-Romance dialects in our second case study (4.2).

Table 1. Parameters of syllable-rhythm and word-rhythm

\begin{tabular}{llll}
\hline Parameter & Syllable rhythm & Word rhythm \\
\hline 1 & Syllable complexity & Low & High \\
2 & Sonority scale & Obeyed & Disobeyed \\
3 & Syllable division & Unambiguos & Ambiguos \\
4 & Assimilations & Few & Many \\
5 & Sandhi & External=internal & External=internal \\
6 & Word-related processes & No & Yes \\
7 & Word accent (phonological) & Fixed or none & Free, \pm grammatical \\
8 & Word accent (phonetic) & Weak & Strong \\
9 & Reduction of unaccented syllables & No & Yes \\
10 Central vowels & No & Yes \\
\hline
\end{tabular}

\subsection{The rhythm class hypothesis: acoustic metrics}

Paradoxically, one outcome of the 'phonological turn' in the isochrony debate was a renewal of the phonetic perspective on speech rhythm. This is mainly due to the publication of an influential study by Ramus, Nespor, and Mehler (1999), who proposed new acoustic measures for the traditional rhythm classes. Instead of searching for equal lengths of time at the syllable or the foot level, other acoustic correlates were formulated that should better fit the phonological parameters of the two rhythm types. The degree of complexity of syllable structure is reflected by $\% \mathrm{~V}$, i.e. the percentage over which an utterance is vocalic, and $\Delta \mathrm{C}$, i.e. the standard deviation of 'consonantal intervals' (consonant clusters regardless of syllable boundaries); the third metric is $\Delta \mathrm{V}$, i.e. the standard deviation of 'vocalic intervals' (vowel sequences regardless of syllable boundaries). The typological predictions are that the syllable-based languages would have a high $\% \mathrm{~V}$ and a low $\Delta \mathrm{C}$ (given their preference for open syllables), whereas accent-based languages would present a low $\% \mathrm{~V}$ and a high $\Delta \mathrm{C}$. The third measure, $\Delta \mathrm{V}$, is supposed to increase in 'stress-timed' languages and to decrease in 'syllabletimed' languages, depending on the degree of strengthening of stressed vowels and the reduction of unstressed vowels. 
At the beginning of the new millennium, the phonetic research paradigm which goes under the heading of 'rhythm class hypothesis' immediately gained a strong interest, also leading to the formulation of alternative metrics. For instance, a methodological improvement of Ramus' metrics has been achieved by Dellwo (2006), who replaced the standard deviation of consonantal intervals by their variation coefficient (Varco) in order to neutralize speech rate effects. A slightly different view of speech rhythm underlies the so-called 'Pairwise Variability Index' (PVI), which calculates the average difference between immediately successive vocalic and consonantal intervals (Grabe and Low 2002).

In our third case study (4.3), we will apply some of these rhythm metrics $(\% \mathrm{~V}, \Delta \mathrm{C}, \Delta \mathrm{V}$; Varco $\mathrm{C}$; $\mathrm{nPVI}-\mathrm{V}, \mathrm{rPVI}-\mathrm{C})$ to speech material available from nine Italo-Romance dialects.

\section{The phonological typology of Italo-Romance dialects}

\subsection{Case study I: vowel systems in Italo-Romance dialects}

A typological study of 58 Italo-Romance dialects (Schmid 1999b: 253254) yielded 44 different vowel systems. The sample cannot be considered to be geographically representative, since 44 dialects of the sample are spoken in northern Italy, where more diversified vowel systems are found.

Comparing our data with the universal tendencies emerging from UPSID (cf. 2.2), the (northern) Italo-Romance vowel systems appear to be more complex and typologically marked. The vowel qualities range from 5 to 13 (UPSID: 2-14), but both the mean (close to 8) and the modal value (7) are clearly superior to the ones in UPSID (close to 6 and 5, respectively). The average number of phonemes in Italo-Romance is even higher (9.43), since many northern dialects display distinctive vowel quantity: $32.8 \%$ against $19.2 \%$ in the first UPSID sample (cf. Maddieson 1984: 129). Long vowels only belong to systems with at least 9 vowel phonemes, thus confirming the 'size principle' (Maddieson 2011: 544) by which complex or marked segments - and it is reasonable to consider long vowels as such are more likely to occur in larger inventories.

Regarding the phonetic content of vowel systems, the Italo-Romance data do confirm a number of universals that have been postulated in the literature. For instance, height distinctions equal or exceed the number of backness distinctions (Universal 9 in Crothers 1978: 134) in all dialects; 
acoustically, this finding can be motivated by the greater robustness of the first vowel formant. A number of northern Italian dialects have rounded front vowels which are typologically marked; in an extended UPSID sample, only $6.6 \%$ of 562 languages do have such phonemes in their inventory (Maddieson 2005d). Conforming with the typological generalization by which "rounded front vowels do not occur unless unrounded front vowels of the same basic height occur" (Maddieson 1984: 14), /y/ implies /i/ in 27 dialects, /ø/ implies /e/ in 21 dialects, and /o/ implies / $/ \varepsilon /$ in 4 dialects. From this picture another implicational universal follows quite naturally: " $/ \varnothing /$ and /œ/ do not occur (separately or together) unless /y/ also occurs" (Maddieson 1984: 14), as holds true for 21 dialects. Finally, phonemically nasal vowels are absolutely marginal in the Italo-Romance area, being attested only in 2 dialects (3.4\% of our sample), against $24 \%$ in the Stanford Phonology Archive and 22.4\% in the first UPSID sample (cf. Crothers 1978: 124, Maddieson 1984: 130); moreover, these two dialects have only few nasal vowel phonemes within a rather large inventory, thus confirming a famous universal formulated by Ferguson (1966: 58; cf. also 2.1).

Returning to the overall number of vowel phonemes and trying to establish a link between segmental and phonotactic typology (cf. 4.2), it is worthy to note that the dialects with a simpler syllable structure also tend to have a lower number of stressed vowel phonemes. At least, this holds true for Sicilian (5), Tuscan (7) and Venetian (7); conversely, dialects with a more complex syllable structure also tend to have a greater number of stressed vowel phonemes: Turinese (9), Milanese (12), Romagnolo (12), Friulian (14). The greater or lesser diversity of vocalic timbres may therefore be related to different degrees of perceptual weight attributed to accented syllables. ${ }^{6}$

\subsection{Case study II: syllable types in Italo-Romance dialects}

As we have seen in 3.2, the first two parameters of the typological framework of syllable and word languages proposed by Auer (1993) are syllable complexity and adherence to the sonority scale (cf. table 1): syllable languages exhibit a simple phonotactics both in quantitative and qualitative terms, whereas the opposite holds for word languages. In this section, we will analyze the phonotactics of ten Italo-Romance dialects in light of these two parameters. A typological continuum was already sketched in a diachronically-oriented study (Mayerthaler 1996), ranging from dialects with a rather unmarked syllable structure (e.g. Sicilian) through dialects of an 
intermediate type (e.g. Neapolitan and Tuscan) to dialects with a rather marked syllable structure (Romagnolo, Piedmontese); note that this continuum is also geographical in that it gradually proceeds from the south to the north of the Italo-Romance area.

In order to verify this hypothesis on synchronic grounds, data have been gathered by inspection of individual dictionaries, considering the following ten dialects: Friulian, Venetian, Feltrino (an alpine Veneto dialect), Milanese, Piedmontese, Romagnolo, Pisan (=Tuscan), Neapolitan, Bitontino (=Apulian), and Sicilian (see Schmid 1998, 2000, submitted, for geographical details and references about the bibliographical sources). The first of the two phonotactic parameters mentioned above - complexity of the syllable shell - can be illustrated by means of the number of possible 'syllable types', i.e. linear sequences of segments ( $\mathrm{CV}, \mathrm{CVC}, \mathrm{CGV}$ etc.) pertaining to three major classes: $\mathrm{C}=$ consonants, $\mathrm{V}=$ vowels, $\mathrm{G}=$ glides; treating glides as a separate category permits highlighting the existence of rising and falling diphthongs in some dialects.

Figure 1 shows that Italo-Romance dialects indeed exhibit a considerable diversity in terms of phonotactic complexity.

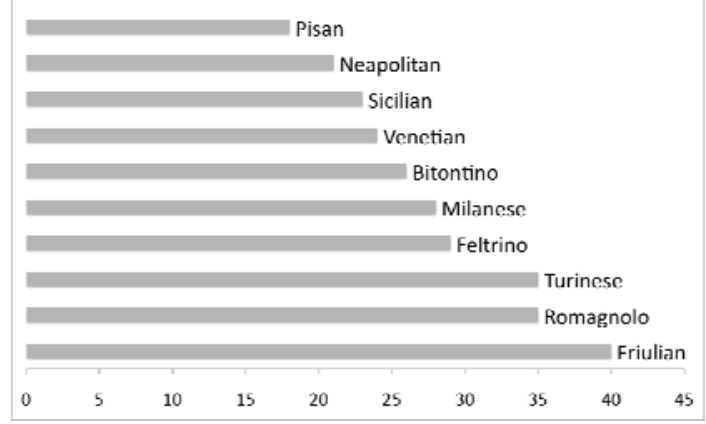

Figure 1. Number of syllable types in ten Italo-Romance dialects

The minimum number of syllabe types (18 in Pisan) is less than half of the maximum (40 in Friulian). Moreover, it is impossible to divide the ten dialects into two clear-cut rhythm types; instead, we are faced with a typological continuum which gradually progresses from the top to the bottom of the graph as the numerical complexity of syllable structure increases. However, the typological continuum does not coincide exactly with a geographical continuum, contrary to Mayerthaler's assumption. It is true that the five dialects in the upper half (which we could categorize as rather accent- or word-based) are all spoken in northern Italy, whereas the majority of the five dialects in the lower part (which we could categorize as rather more 
syllable-based) are spoken in central or southern Italy; nevertheless, among the syllable-based dialects we also find one northern dialect, Venetian; moreover, the most simple syllable structure appears in the center of Italy, i.e. in Pisa, and not in the south, e.g. in Sicily (cf. 4.3); this is somewhat surprising, since some scholars (e.g., Mayerthaler 1996: 209) actually attribute a strong preference for CV syllables to Sicilian; however, one should bear in mind that this dialect also has many closed syllables due to diachronic gemination (cf. Schmid 1997: 259).

Now turning to the second phonotactic parameter, i.e. sonority relations in syllable heads and codas, we can distinguish between three subtypes among the five dialects in the lower part of Figure 1. The first subtype consists of Milanese and Feltrino, which - besides having a numerically less complex syllable structure - also exhibit less marked sonority relations. Word-initially, Milanese and Feltrino order consonants like the syllablebased dialects, mainly combining obstruents with vibrants or approximants, whereas word-finally they allow clusters of two consonants like $/ \mathrm{rn} /, / \mathrm{st} /$ or $/ \mathrm{nt} /$; this pattern is absent in the syllable-based dialects, but nevertheless conforms to the sonority scale. The second subtype is represented by Friulian, which contains the most marked syllables in terms of numerical complexity, while essentially adhering to the sonority principle (albeit in a less exemplary way): word-initially, it also permits clusters with laterals such as $/ \mathrm{kl} /$, and word-finally we find triconsonantal clusters like [nks] with a sonority reversal due to the sigmatic plural. Finally, the most marked sonority relations occur in the third subtype, represented by Piedmontese and Romagnolo - a finding which is in line with Mayerthaler's continuum. For instance, these dialects allow word final sequences with two stops like salvätk; sonority plateaus also appear at the left periphery of the phonological word, as is shown by examples like vsen or pké. The most marked clusters consist of three obstruents, like in sbdel or pské, which may also be followed by an additional vibrant, as in vspre or pstren (see Schmid, submitted, for additional examples and a more detailed analysis of the consonantal clusters).

\subsection{Case study III: applying the rhythm metrics to Italo-Romance dialects}

In order to test the rhythm class hypothesis for the Italo-Romance dialect continuum, a corpus has been built with speech data for the same dialects that had been subject to the phonotactic analysis in 4.2 , with the exception 
of Romagnolo for which no publicly available data could be found; for each dialect ten utterances have been analyzed acoustically.

Figure 2 compares two alternative rhythm metrics, $\Delta \mathrm{C}$ and Varco $\mathrm{C}$, projected against $\% \mathrm{~V}$. The rhythm class hypothesis predicts that syllablebased dialects (represented with circles) should be placed at the center of the plane, whereas accent- or word-based dialects (represented with rhombi) are located in the upper part to the left.
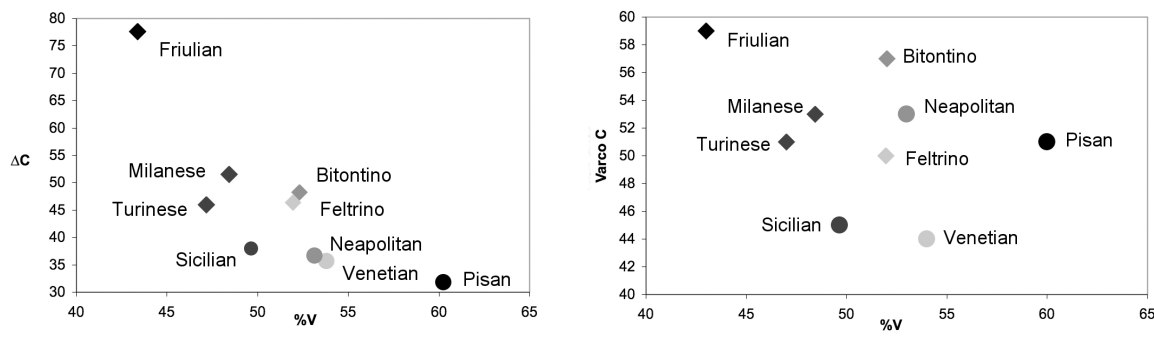

Figure 2. $\% \mathrm{~V}, \Delta \mathrm{C}$ (left) and $\% \mathrm{~V}$, VarcoC (right) for 9 Italo-Romance dialects

Comparing the horizontal axis of the two planes in Figure 2 with Figure 1 above, one notes a certain coincidence in the ordering of the dialects, suggesting that $\% \mathrm{~V}$ can indeed be interpreted as an acoustic correlate of syllable complexity (or at least of the preference for open syllables); for instance, we notice both in Figure 1 and in Figure 2 a rather peripheral position of Friulian and Turinese (accent-based) and of Pisan (syllablebased). In analogy with the phonotactic data (cf. 4.2), Pisan shows a much higher $\% \mathrm{~V}$ than Sicilian. Milanese remains a bit more left than Bitontino and Feltrino in Fig. 2, but these three dialects are still located in a relatively central area of the rhythm plane. In both Figure 1 and Figure 2 Neapolitan and Venetian tend towards the syllable-based pole of the continuum.

As regards the vertical axis, which reflects the complexity of consonantal clusters, the two planes of Figure 2 report different measures. It appears that the extreme position of Friulian in the diagram on the left is not only due to the heavy consonantal clusters of the language (cf. 4.2), but also to the slow speech rate of the recorded speaker. The normalization effect of Varco (an important methodological improvement) also affects Feltrino which moves towards the syllable-based bottom, whereas Neapolitan and Bitontino (two geographically related dialects) move towards the accentbased top.

Figure 3 again compares two rhythm metrics for the durations of vocalic and consonantal intervals (cf. 3.3), i.e. the standard deviations to the left 
(according to Ramus, Nespor, and Mehler 1999) and the 'Pairwise Variability Indices' (PVI; cf. Grabe and Low 2002) to the right. ${ }^{7}$
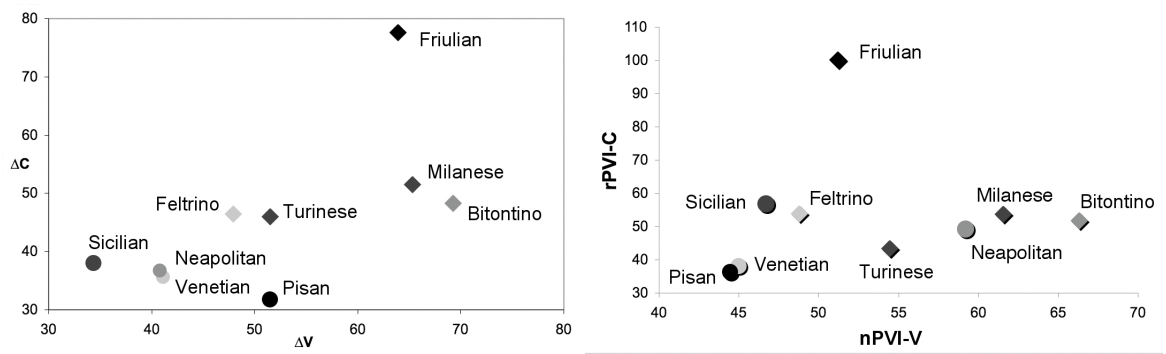

Figure 3. $\Delta \mathrm{V}, \Delta \mathrm{C}$ (left) and PVI values (right) for 9 Italo-Romance dialects

All in all, the results differ less than one would expect. On the consonantal axis, Friulian again appears in a position by itself, since both $\Delta \mathrm{C}$ and rPVI$\mathrm{C}$ are not normalized for speech rate; as a methodological consequence, our data underpin the need of rate normalization for rhythm metrics. Still on the vertical axis, Sicilian moves up in the PVI plane, maybe due to subsequent singleton and geminate intervals. On the horizontal axis (where the PVI adopts a normalized measure), differences are more tangible: Pisan shifts to the left, revealing a more regular ('isovocalic') pattern, whereas the dramatic move towards the right of Neapolitan can be explained by the heavy reduction of unaccented vowels (a phenomenon which also characterizes the Apulian dialect of Bitonto). From a methodological point of view it seems therefore that the more global $\Delta \mathrm{C}$ metric indeed reflects syllable complexity, but that the sequential vocalic PVI approach is better suited for another parameter of rhythm typology, i.e. vowel reduction.

\section{Concluding remarks}

Where do we go from here? From the few insights we have gained in this short tour d'horizon, phonological typology appears as a somewhat neglected, but nevertheless promising - and hopefully soon flourishing - field of linguistic inquiry that presents a rich research agenda but also a number of methodological problems. Segmental typology comes with a solid and steadily growing body of well-organized data, providing us with a number of empirically tested implicational universals. The descriptive value of prosodic typology can be taken for granted, at least as far as single parameters like accent or tone are concerned; one can also reasonably assume that 
phonological typologists know the basic dynamics of phonotactics in the languages of the world, despite the controversies that may exist with regard to the appropriate formal analysis of syllable structure.

Do phonologically defined 'language types' exist? This is still a matter of debate, and some scholars cast doubts on the feasibility of a holistic typology with regard to phonology. For instance, Schiering (2007) tested ten phonotactic, prosodic and morphonological parameters, finding that in a sample of 20 representatively chosen languages only six of the parameters proposed by Auer (1993) correlated significantly with the alleged rhythm types; nevertheless, he concludes that languages may be situated on a typological continuum ranging from a mora-based to a stress-based pole.

The purpose of the three case studies summarized in the present paper has been somewhat less ambitious. On the one hand, our research aimed at verifying the methodological value of a 'limited' typology, operating within a genetically and geographically restricted dialect group. The first case study on vowel systems not only permitted to position the Italo-Romance dialects within the 'typological space' of the world's languages; it also allowed to demonstrate the validity of a number of implicational universals within the 'limited' sample. The second case study provided evidence in favour of two parameters of Auer's (1993) dichotomy of word-based and syllable-based languages: Italo-Romance dialects can be ordered on a continuum of increasing numerical syllable complexity, and some of the more word-oriented dialects heavily run counter the unmarked sonority relations. Finally, the third case study showed that a phonetic study of speech rhythm yields relatively robust acoustic correlates of syllable complexity, demonstrating that the research tools developed by the 'rhythm class hypothesis' may function as a companion to phonological typology. Here again, analyzing dialects from a restricted area may provide results that are similar to the findings of general phonetic typology, given that in a sample of 22 genetically balanced languages, complex syllables correlate with higher $\Delta \mathrm{C}$ and lower \%V values: as a matter of fact, "in a multiple regression analysis, syllable structure has a significant effect on both $\Delta \mathrm{C}$ and $\% \mathrm{~V}$ at the $\mathrm{p}<0.005$ level" (Easterday, Timm and Maddieson 2011: 625).

This finding obviously raises the final methodological question about the relationship between phonetics and phonology. More than eighty years after the theses of the Prague circle, the two linguistic subdisciplines have indeed developed in separate directions to a large extent. Nevertheless, there is reason to argue that both linguistic typology and acoustic investiga- 
tions contribute in a complementary manner to our understanding of phonological structure.

\section{Notes}

1. The marginality of phonology has possibly always been inherent in typological linguistics throughout its history, if we consider Martinet's (1962: 69-70) complaint that language classifiers concentrate on morphological features and his plea for phonology as an essential part of linguistic typology.

2. Obviously, linguistic typology is presented here in a somewhat 'traditional' manner; see Zúniga (this volume) for recent developments in this field.

3. This version can be accessed online at: http://web.phonetik.uni-frankfurt.de/upsid.html

4. Note, however, that phonological universals represent statements about structural properties of phonological systems. They can be explained through 'mechanistic' constraints of speech production and perception, but they are not to be confused with phonetic universals stricto sensu such as i) "higher vowels have higher f0 than lower vowels", ii) "higher vowels are shorter than lower vowels", iii) "the vowel before a voiced consonant is longer than that before its voiceless counterpart" (Maddieson 1997: 624).

5. See, in particular, van der Hulst, Goedemans and van Santen (2010). An online version of the database is available at http://www.unileiden.net/stresstyp/.

6. Unfortunately, we do not have data about the unstressed vowel systems at our disposal, which is a crucial element of rhythm typology (cf. 3.2).

7. Note that in the PVI plane the vocalic and consonantal axes have been inverted with respect to the representation in Grabe and Low (2002: 530) in order to make it comparable with the $\Delta \mathrm{V} / \Delta \mathrm{V}$-plane (cf. Ramus 2002).

\section{References}

Abercrombie, David

1967 Elements of general phonetics. Edinburgh: Edinburgh University Press.

Auer, Peter

1993 Is a rhythm-based typology possible? A study on the role of prosody in phonological typology. KontRI Working paper No 21.

2001 Silben- und akzentzählende Sprachen. In Haspelmath et al. (eds.), 1391-1399 (Teilband 2). 
Auer, Peter, and Susanne Uhmann

1988 Silben- und akzentzählende Sprachen. Literaturüberblick und Diskussion. Zeitschrift für Sprachwissenschaft 7: 214-259.

Bertinetto, Pier Marco

1989 Reflections on the dichotomy 'stress vs. syllable timing'. Revue de phonétique appliquée 91-92-93: 99-130.

Croft, William

1990 Typology and universals. Cambridge: Cambridge University Press.

Crothers, John

1978 Typology and universals of vowel systems. In Greenberg et al., (eds.), 93-152.

Dauer, Rebecca

1983 Stress-timing and syllable-timing reanalyzed. Journal of Phonetics 11: 51-62.

Delattre, Pierre

1965 Comparing the phonetic features of English, German, Spanish and French. Heidelberg: Julius Groos.

Dellwo, Volker

2006 Rhythm and speech rate: a variation coefficient for DeltaC. In Language and language processing: proceedings of the $38^{\text {th }}$ Linguistics Colloquium, Paweł Karnowski and Imre Szigeti (eds.), 231-241. Frankfurt: Lang,

Donegan, Patricia, and David Stampe

1983 Rhythm and the holistic organization of language structure. In $\mathrm{Pa}$ pers from the parasession on the interplay of phonology, morphology and syntax, John F. Richardson, Mitchell Marks, and Amy Chukerman (eds.), 337-353. Chicago: Chicago Linguistic Society.

Easterday, Shelece, Jason Timm, and Ian Maddieson

2011 The effects of phonological structure on the acoustic correlates of rhythm. In Proceedings of the $17^{\text {th }}$ International Congress of Phonetic Sciences, Wai-Sum Lee and Eric Zee (eds.), 623-626. Hong Kong.

Ferguson, Charles

1966 Assumptions about nasals: a sample study in phonological universals. In Greenberg (ed.), 53-60.

Gil, David

1986 A prosodic typology of language. Folia Linguistica 20: 165-231.

Grabe, Esther, and Ee Ling Low

2002 Durational variability in speech and the Rhythm Class Hypothesis. In Laboratory Phonology 7, Carlos Gussenhoven and Natasha Warner (eds.), 515-545. Berlin/New York: Mouton de Gruyter. 
Greenberg, Joseph (ed.)

1966 Universals of grammar. Second edition. Cambridge, Massachussets: MIT Press.

Greenberg, Joseph

1966a Some universals of grammar with particular reference to the order of meaningful elements. In id. (ed.), 73-113.

1966b Language universals, with special reference to feature hierarchies. The Hague: Mouton.

1978 Some generalizations concerning initial and final consonant clusters. In Greenberg et al. (eds.), 243-279.

Greenberg, Joseph, Charles Ferguson, and Edith Moravcsik (eds.)

1978 Universals of human language. Vol. II: Phonology. Stanford: Stanford University Press.

Haspelmath, Martin, Ekkehard König, Wulf Oesterreicher, and Wolfgang Raible (eds.)

2001 Sprachtypologie und sprachliche Universalien, 2 Halbbände. Berlin/New York: Mouton de Gruyter.

Haspelmath, Martin, Matthew Dryer, David Gil, and Bernard Comrie (eds.)

2005 The World Atlas of Language Structures. Oxford: Oxford University Press (online version 2008: wals.info)

Hirst, Daniel, and Albert Di Cristo

1998 Intonation patterns. Cambridge: Cambridge University Press.

Hulst, van der Harry, and Bob Goedemans

2005 Rhythm types. In Haspelmath et al. (eds.), 74-77.

Hulst, van der Harry, Bob Goedemans, and Ellen van Santen (eds.)

2010 A survey of word accentual patterns in the languages of the world. Berlin/New York: de Gruyter.

Hyman, Larry

2001 Tone systems. In Haspelmath et al. (eds.), 1367-1380.

2007 Where's phonology in typology? Linguistic Typology 11: 265-271.

Ineichen, Gustav

1991 Allgemeine Sprachtypologie. Ansätze und Methoden. Darmstadt: Wissenschaftliche Buchgesellschaft.

Jakobson, Roman

1941 Kindersprache, Aphasie und allgemeine Lautgesetze. Uppsala Universitets Arsskrift: 1-83.

Jun, Sun-Ah

2005 Prosodic typology. The phonology of intonation and phrasing. Oxford: Oxford University Press.

Keller, Kathrin

2008 "Hützt's z'Zuzwil?" Zu den Silbenstrukturen des Schweizerdeutschen, empirisch analysiert an zwei Dialekten. Master Thesis, University of Berne. 
Liljencrants, Johan, and Björn Lindblom

1972 Numerical simulations of vowel quality systems: the role of perceptual contrast. Language 48: 839-862.

Maddieson, Ian

1978 Universals of tone. In Greenberg et al. (eds.), 335-365.

1984 Patterns of sounds. Cambridge: Cambridge University Press.

1997 Phonetic universals. In The Handbook of Phonetic Sciences, William J. Hardcastle and John Laver (eds.), 619-639. Oxford: Blackwell.

2005a Consonant inventories. In Haspelmath et al. (eds.), 10-13.

2005b Vowel quality inventories. In Haspelmath et al. (eds.), 14-17.

2005c Consonant-vowel ratio. In Haspelmath et al. (eds.), 18-21.

2005d Front rounded vowels. In Haspelmath et al. (eds.), 50-53.

2005e Syllable structure. In Haspelmath et al. (eds.), 54-57.

$2005 \mathrm{f}$ Tone. In Haspelmath et al. (eds.), 58-61.

2011 Typology of phonological systems. In The Oxford handbook of linguistic typology, Jae Jung Song (ed.), Oxford: Oxford University Press: 534-548.

Maddieson, Ian, and Kristin Precoda

1990 Updating UPSID. UCLA Working papers in phonetics 74: 104-114.

Martinet, André

1962 A functional view of language. Oxford: Clarendon.

Mayerthaler, Eva

1996 Stress, syllables, and segments: their interplay in an Italian dialect continuum. In Natural Phonology: the State of the Art, Bernhard Hurch, and Richard A. Rhodes (eds.), 201-221. Berlin/New York: Mouton de Gruyter.

Milewski, Tadeusz

1970 Voraussetzungen einer typologischen Sprachwissenschaft. Linguistics 59: 62-107.

Pike, Kenneth

1947 The intonation of American English. Ann Arbor: The University of Michigan Press.

Ramus, Franck

2002 Acoustic correlates of linguistic rhythm: perspectives. In Speech Prosody 2002. Aix-en-Provence: 115-120.

Ramus, Franck, Marina Nespor, and Jaques Mehler

1999 Correlates of linguistic rhythm in the speech signal. Cognition 73: 265-292.

Schiering, René

2007 The phonological basis of linguistic rhythm: cross-linguistic data and diachronic interpretation. Sprachtypologie und Universalienforschung 60: 337-359. 
Schmid, Stephan

1997 A typological view of syllable structure in some Italian dialects. In Certamen Phonologicum III, Pier Marco Bertinetto, Livio Gaeta, Georgi Jetchov, and David Michaels (eds.), 247-265. Torino: Rosenberg \& Sellier.

1998 Tipi sillabici nei dialetti dell'Italia settentrionale. In Atti del XXI Congresso Internazionale di Linguistica e Filologia Romanza. Vol. 5. Dialettologia, geolinguistica, sociolinguistica, Giovanni Ruffino (ed.), 613-625. Tübingen: Niemeyer.

1999a Fonetica e fonologia dell'italiano. Torino: Paravia.

1999b Per un'analisi del vocalismo italo-romanzo in chiave tipologica. In Fonologia e morfologia, Paola Benincà, Alberto Mioni, and Laura Vanelli (eds.), 249-267. Roma: Bulzoni.

2000 Tipi sillabici in alcuni dialetti centro-meridionali. In Actes du XXIIe Congrès international de linquistique et philologie romanes. Tome III: Vivacité et diversité de la variation linguistique, Annick Englebert et al. (eds.), 343-350. Tübingen: Niemeyer.

subm. Syllable typology and the rhythm class hypothesis: evidence from Italo-Romance dialects. In Phonological typology of syllable and word languages in theory and practice, Javier Caro Reina and Renata Szczepaniak (eds.). Berlin/New York: Mouton de Gruyter.

Schwartz, Jean-Luc, Louis-Jean Boë, Nathalie Vallée, and Christian Abry

1997 The dispersion-focalization theory of vowel systems. Journal of Phonetics 25: 255-286.

Siebenhaar, Beat, and Adrian Leemann

this vol. Methodological reflections on the phonetic-phonological continuum, illustrated on the prosody of Swiss German dialects.

Trubetzkoy, Nikolaj

1939 Grundzüge der Phonologie. Prague: Ministère de l'instruction publique de la République Tchéco-Slovaque.

Vennemann, Theo

1988 Preference laws for syllable structure and the explanation of sound change. Berlin: Mouton de Gruyter.

Zúñiga, Fernando

this vol. Language description and linguistic typology. 